\title{
MIOGÊNESE DO TECIDO MUSCULAR BRANQUIAL DO PEIXE EURIALINO Poecilia vivipara (Cyprinodontiformes, Poeciliidae) EXPOSTO À SALINIDADE
}

\author{
Adriana Maria Antunes ${ }^{1}$; Thiago Lopes RochA ${ }^{1}$; José OsCAR Rodrigues Morais ${ }^{1}$; Simone \\ MARIA TEIXEIRA SABÓIA-MORAIS ${ }^{1}$ \\ ${ }^{1}$ Laboratório de Comportamento Celular, Instituto de Ciências Biológicas, Universidade Federal de Goiás, \\ Goiânia-Go 74001-970, Campus II, ICB IV, Goiânia, Goiás, Brasil. - adrianaantunesbio@gmail.com, \\ simonesaboias@gmail.com
}

\section{RESUMO}

Os teleósteos Poecilia vivipara, conhecidos popularmente como guarus, são caracterizados como eurialinos, ou seja, eles modulam o comportamento celular branquial para sobreviver em ambientes com variações de salinidade. As brânquias do P.vivipara possuem um conjunto de músculos estriados esqueléticos, os músculos adutores e abdutores, que têm papel importante no processo de respiração. O presente trabalho teve como objetivos principais descrever a morfologia das estruturas musculares branquiais durante os estágios iniciais do seu desenvolvimento e realizar uma caracterização morfológica inicial em guarus adultos. Além disso, visouse analisar os efeitos das diferentes concentrações de salinidade nas características morfológicas das fibras musculares branquiais de alevinos. Como resultados das investigações, observou-se que as fibras musculares são formadas entre a fase 2 e 3 do desenvolvimento embrionário. Nesse estágio de desenvolvimento, os músculos branquiais estão inseridos na porção basal do filamento branquial, possivelmente no tabique de cartilagens que suporta as brânquias, e organizados em feixes musculares localizados ao longo do filamento branquial. Essa organização morfológica permanece nos adultos. Detectou-se um aumento no diâmetro das fibras e dos feixes musculares em alevinos expostos a concentrações de sal marinho, o que permite relacionar o tamanho corporal dos guarus com o grau de salinidade do ambiente onde vivem.

PALAVRAS-CHAVE: guaru; músculo branquial; ontogênese; salinidade.

\section{MYOGENESIS OF GILL MUSCLE TISSUE OF THE EURYHALINE FISH Poecilia vivípara (Cyprinodontiformes, Poeciliidae) EXPOSED TO SALINITY}

The teleost Poecilia vivipara are characterized as euryhaline, in other words, they modulate gill cell behavior to survive in environments with varying salinity. P.vivipara gills have a set of striated skeletal muscles, abductor and adductor muscles, which plays an important role in the respiration process. This study aimed to describe the morphology of gill muscles during the early stages of development and perform an initial morphological characterization of adults P.vivipara. Moreover, it aimed to analyze the effects of different concentrations of salinity on the morphological characteristics of muscle fibers in fingerlings' gills.
Results showed that the muscle fibers are formed between phases 2 and 3 of embryonic development. At this stage of development, gill muscles are inserted into the basal portion of gill filament, possibly in the bulkhead of cartilage that supports the gills, and organized in muscle bundles located along the gill filament. This morphological organization remains in adults. An increase in the diameter of the fibers and muscle bundles was observed in fingerlings exposed to concentrations of sea salt, which allows relating the body size of P.vivipara with the degree of salinity of the environment where they live.

KEYWORDS: guppy; gill muscle; ontogeny; salinity. 


\section{INTRODUÇÃO}

Os representantes da Classe Pisces, subclasse Teleostei, mostraram ao longo da evolução séries de adaptações morfofuncionais que os permitiram povoar ambientes diversos. Dentre os teleósteos, o gênero Poecilia, conhecidos popularmente como guarus ou barrigudinhos, são caracterizados como larvófagos, onívoros, cosmopolitas do continente americano e eurialinos, ou seja, sobrevivem e reproduzem em ambientes com variações de salinidade que vai desde a condição de água doce (0 ppm) (AD) até a água salobra (20 ppm) (AS). Dessa maneira, os Poecilia são resistentes às condições adversas do ambiente aquático e considerados bons modelos biológicos para estudos de toxicidade (SABÓIA-MORAES et al., 1996).

$\mathrm{O}$ guaru modula o comportamento celular branquial para sobreviver em ambientes com variações de salinidade (SABÓIA-MORAES et al., 1996). Isso porque as brânquias possuem papéis vitais para os peixes, atuando como sítios de trocas gasosas, em processos de íon/osmorregulação, equilíbrio ácidobásico, excreção de compostos nitrogenados e gustação (LAURENT et al., 1985; MOYLE et al., 1996; DÍAZ et al., 2005; VIGLIANO et al., 2006).

$\mathrm{O}$ guaru possui quatro pares de arcos branquiais constituídos de numerosos filamentos branquiais, os quais possuem lamelas secundárias. Segundo JOBLING (1995), as lamelas secundárias representam a superfície funcional respiratória, por onde o oxigênio é absorvido da água e difundido ao sangue e aos tecidos.

As brânquias são compostas por dois tipos de músculos estriados esqueléticos, abdutor e adutor (BURLESON et al., 2001). Essa musculatura dos filamentos branquiais desempenha a ação de bombear a água através das brânquias, atuando no direcionamento do fluxo da água (cavidade faríngea - cavidades operculares - meio externo), tendo então papel nos mecanismos de respiração (BALLINTIJN et al., 1985).

Existem três tipos de fibras musculares, a intermédia, a vermelha e a branca, cuja distribuição e frequência determinam as características metabólicas e contráteis do músculo esquelético, revelando suas propriedades bioquímicas e fisiológicas (PETER et al., 1972). O músculo branco compreende cerca de $70 \%$ da massa miotomal e corresponde à parte comestível dos peixes (ZHANG et al., 1996), possui metabolismo glicolítico e contração rápida (DRIEDZIC et al., 1976). O músculo vermelho possui metabolismo aeróbico e contração lenta (LUTHER et al., 1995; JONHSTON et al., 1977). Existe uma camada muscular com características intermediárias entre o músculo branco e vermelho; essa massa muscular juntamente com a musculatura vermelha representa $30 \%$ do total da massa muscular. A coloração das fibras musculares é também um indicativo do grau de vascularição. Assim, as fibras vermelhas são muito vascularizadas e têm a aparência escura devido ao alto teor de mioglobina, o que facilita a perfusão de oxigênio para o músculo, dotanto-o de alta capacidade para o metabolismo oxidativo. Em contraste, o músculo branco apresenta menor vascularização e possui fibras capazes de produzir energia na ausênia de oxigênio (SANTOS, 2007). Neste sentido, o fenótipo dos tipos de fibras musculares adultas resulta de eventos que ocorrem desde a fase embrionária e vários genes estão envolvidos nesse processo de diferenciação (SARTORI et al., 2001).

A miogênese é o processo de formação do tecido muscular e é um mecanismo plástico que envolve um conjunto de células precursoras miogênicas chamadas de mioblastos (JOHNSTON, 1999). Os mioblastos são células indiferenciadas presentes no miótomo que vão se especificar em miócitos e dar origem às fibras musculares. Durante o desenvolvimento muscular, uma população de mioblastos não se diferencia, permanecendo associada à periferia da fibra muscular, entre a lâmina basal e o sarcolema, como células satélites musculares quiescentes (SCHULTZ \& MCCORMICK, 1994). As células satélites possuem grande atividade mitogênica e a sua progênie pode se fundir formando novas fibras musculares, ou mesmo se unir às fibras musculares já existentes. Dessa forma, elas contribuem para o crescimento, reparo e manutenção do músculo esquelético (HAWKE, 2001). A forma ativa das células satélites, assim como as células precursoras musculares durante as fases iniciais de desenvolvimento é denominada de mioblasto (RANTANEN et al., 1995).

Para os vertebrados é comum que em alguns aspectos a ontogênese remonte a filogênese (CARVALHO NETO \& TOURINHO, 2001). Nesse sentido, mesmo considerando outros grupos do filo Chordata (BEASTER-JONES, 2006), é possível verificar que durante a embriogênese a mesoderme paraxial origina os somitos ventromedial e dorsomedial. O somito ventromedial é responsável pela formação do esclerótomo mesenquimal que vai originar o esqueleto axial e as costelas. O somito dorsomedial origina o dermomiótomo que forma os derivados cutâneos e o miótomo. Assim, fatores de crescimento e de transcrição atuam juntos durante a formação do miótomo, de forma que o somito e estruturas adjacentes (ectoderme, tubo neural, notocorda e estruturas vasculares) darão origem ao tecido muscular após varias reações moleculares (HAWKE et al, 2001).

$\mathrm{O}$ conhecimento da miogênese do tecido muscular permite não somente a compreensão dos mecanismos morfofuncionais dos músculos presentes nos filamentos branquiais, como também o entendimento da composição química e da citofisiologia a ser comparada com a de outras regiões corpóreas e com os peixes de interesse comercial. De 
acordo com SALES \& SALES (1990), a musculatura de peixes é considerada de grande importância para formulação de dietas nutritivas apropriadas, sendo de amplo valor econômico para as indústrias de pescado.

A compreensão acerca da miogênese do guaru também contribuirá para os estudos de toxicologia experimental e ecotoxicologia aquática. Isso porque o guaru é um biomonitor da poluição aquática e o tecido muscular é um órgão bioacumulador de vários elementos tóxicos presentes nos corpos d'água (VARSHNEY, 1991).

Objetivou-se com o presente trabalho descrever a morfologia das estruturas musculares durante a diferenciação e organização das fibras musculares estriadas esqueléticas branquiais do Poecilia vivipara nos estágios iniciais do seu desenvolvimento, focando as fases de embrião, larva e alevino. Visou-se analisar a interferência da exposição dos alevinos a diferentes concentrações de salinidade nas características morfológicas das fibras musculares branquiais. Além disso, realizou-se nos espécimes adultos uma caracterização morfológica inicial do músculo estriado esquelético branquial.

\section{MATERIAL E MÉTODOS}

Os espécimes de Poecilia vivipara foram coletados em tanques do setor de piscicultura da Escola de Medicina Veterinaria e Zootecnia da Universidade Federal de Goiás, onde os tanques correspondiam às águas continentais habituais da espécie. Eles foram levados à experimentação no Laboratório de Comportamento Celular, do Instituto de Ciências Biológicas, Departamento de Morfologia.

Para tal estudo foram necessárias 30 fêmeas de guaru gestantes em estágios de prenhês distintos. Os animais foram aclimatados por um período de 48 horas em tanque com 40L de água doce (AD). A água, originalmente destinada ao abastecimento urbano, foi filtrada e o resíduo de cloro foi eliminado por meio de aeração, sendo assim utilizada água declorinada. Durante o período de aclimatação, os índices de oxigênio e amônia foram medidos através de Kits da LABCON TEST ${ }^{\circledR}$, e os parâmetros de temperatura, luminosidade e salinidade foram acompanhados. Os peixes foram alimentados com ração comercial ALCON COLOURS ${ }^{\circledR}$.

Os espécimes utilizados foram divididos em dois grupos. No primeiro grupo 15 fềmeas foram sacrificadas por decapitação e do seu ventre coletados embriões em diferentes estágios de desenvolvimento, sendo o estágio de cada espécime avaliado através de microscopia estereoscópica. Além da coleta dos embriões, foram coletados deste grupo de fêmeas os arcos branquiais, para a análise das brânquias de espécimes adultos. As demais fêmeas, que constituíram o segundo grupo, foram divididas em tanques maternidades e assim mantidas até o nascimento dos alevinos. Ao nascer, os alevinos foram retirados da água doce $(\mathrm{AD})$ e expostos à água com diferentes salinidade ( $0 \%$, 5\%, $10 \%$, $15 \%$ e $20 \%$ ) (sal marinho comercial Coralife - USA), em sistema estático sem renovação da água, por um período total de 2 horas. Foram colhidos 25 alevinos e utilizados cinco para cada tratamento.

Após a coleta de embriões, larvas e alevinos, esse material biológico foi fixado por imersão em Karnovsky (KARNOVSKY, 1965), por duas horas, e mantidos em álcool etílico $70 \%$. Em seguida, o material foi incluso em historessina (Leica Historesin $($ ) e seccionados com $1 \mu \mathrm{m}$ de espessura no ultra-micrótomo (Leica Ultracut UCT ${ }^{\circledR}$ ). Os cortes foram submetidos à coloração de azul de toluidina aquoso a 1\%, pH 8,4, para a visualização da organização geral das fibras musculares. Os arcos branquiais oriundos dos espécimes adultos foram inclusos em paraplast, seccionados a $4 \mu \mathrm{m}$ de espessura e corados com Hematoxilina-Eosina. As fotodocumentações foram realizadas por meio do fotomicroscópio (LEICA DMLB $®$ ).

A análise morfométrica foi realizada no tecido muscular branquial dos alevinos expostos a variações de salinidade. Foram sorteados dois espécimes de cada tratamento com salinidade, totalizando o sorteio de três lâminas e cinco cortes de cada espécime por tratamento. A morfometria foi realizada por meio das fotomicrografias cujas imagens foram ampliadas em 400 vezes. Os parâmetros histométricos utilizados foram os diâmetros das fibras e diâmetro dos feixes musculares branquiais. Dessa forma, em cada imagem capturada foram mensurados os diâmetros supracitados utilizando-se o programa IMAGE PRO-PLUS 6.0 (Microsoft ${ }^{\circledR}$ Window 32-bit sistems Window ${ }^{\circledR}$ XP Professional). A análise estatística baseou-se no teste de análise de variância (ANOVA) e no teste de Tukey para comparações múltiplas, por meio do programa BioEstat 4.0, adotando-se nível de significância igual a $5 \%(\alpha=0,05)$.

\section{RESULTADOS E DISCUSSÃO}

Estudos preliminares da ontogênese do Poecilia vivipara identificaram oito fases do desenvolvimento por meio das quais é possível a distinção das características morfológicas observadas ao microscópio estereoscópico: Fase 1, ovo rico em vitelo; Fase 2, embrião com formato arredondado e início da formação do globo ocular; Fase 3, embrião ainda circundando o vitelo, com olhos e região dorsal pigmentados; Fase 4, larva com formato cilíndrico, apresentando saco vitelínico externalizado, com grande quantidade de vitelo; Fase 5, larva com redução do saco vitelínico e com pigmentação acentuada do dorso; Fase 6, larva com pouco vitelo externalizado, indivíduo 
próximo ao nascimento; Fase 7, alevino ou pós-nascido com livre natação e apto a explorar o ambiente externo ao corpo materno; Fase 8, espécime jovem, com início da maturação sexual.

É possível observar o início da formação das brânquias no $P$. vivípara entre as fases 2 e 3 juntamente com a formação da nadadeira caudal e do globo ocular. Como nesta fase ocorrem intensas modificações morfológicas, supõe-se que a migração das células precursoras que darão início à formação das fibras musculares diferenciadas também tenha início. Inferese então que, simultaneamente ao desenvolvimento das brânquias no $P$. vivípara, ocorre a miogênese do músculo estriado esquelético branquial.

A partir da fase 3 do desenvolvimento é possível observar a presença do músculo estriado esquelético branquial (Figuras 1 e 2). Os músculos branquiais estão inseridos na porção basal do filamento branquial, possivelmente no tabique de cartilagens que suporta as brânquias. A partir desse ponto de inserção cada tipo muscular se origina de um lado do vaso sanguíneo localizado abaixo da cartilagem (Figura 3), sendo que os músculos adutores localizam-se entre as bases dos filamentos branquiais e os abdutores têm as suas fibras prolongadas ao longo do filamento branquial (Figura 4). Essa organização do tecido muscular pode ser observada a partir da fase 3 de desenvolvimento, e estudos da morfologia do músculo estriado esquelético branquial utilizando espécimes adultos, em que as brânquias já estão completamente desenvolvidas, podem confirmar essa localização e organização do músculo branquial.

Ao longo dos estágios de embrião, larva e alevino, é possível observar o aumento gradual no diâmetro dos feixes musculares branquiais. A ontogênese do tecido muscular e a ativação dos tipos de fibras musculares até os momentos finais do desenvolvimento embrionário são de grande importância. O funcionamento do músculo estriado esquelético branquial é de grande valor para o alevino uma vez que, ao nascer, ele necessitará das atividades musculares para os mecanismos de respiração e para a obtenção de energia, o que possibilitará a livre natação e a fuga de predadores.
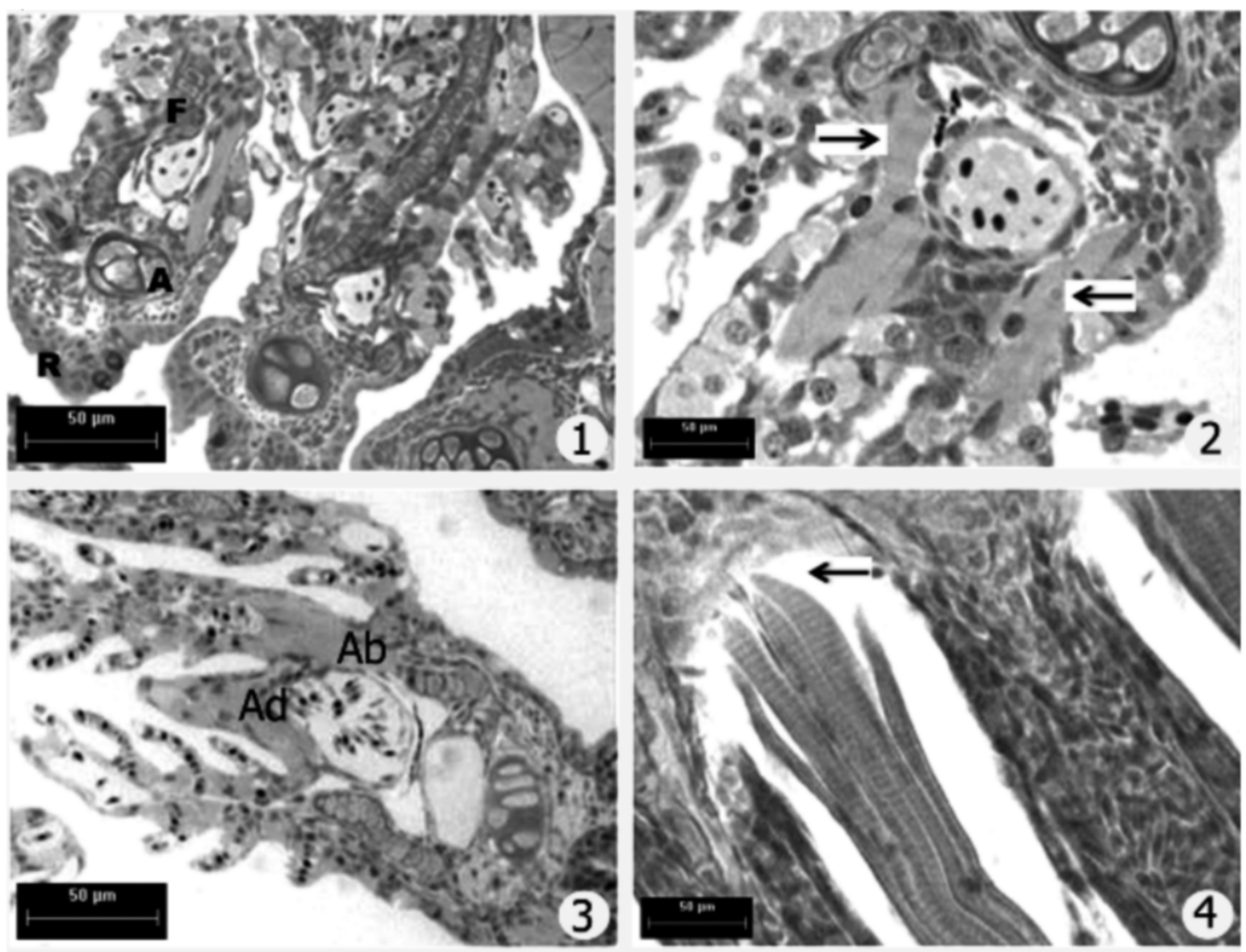

Figuras 1 a 4. Fotomicrografia evidenciando a formação das brânquias durante a fase 3 do desenvolvimento embrionário e a morfologia do músculo branquial em espécime adulto. 1. Arco branquial cartilaginoso que suporta as brânquias (A), filamento branquial (F) e rastelo (R), Barra $=50 \mu \mathrm{m}$. 2. Músculo estriado esquelético branquial, inserção dos músculos adutores e abdutores (setas) Barra $=100 \mu \mathrm{m}$. 3. Músculo adutor localizado entre as bases dos filamentos branquiais (Ad) e músculo abdutor localizado ao longo do filamento branquial ( $\mathrm{Ab}$ ). Barra $=100 \mu \mathrm{m}$. 4. Inserção do músculo estriado esquelético branquial em espécimes adultos (seta) Barra=100 $\mu \mathrm{m}$. 
A análise morfométrica do músculo estriado esquelético branquial de alevinos expostos a diferentes concentrações de salinidades mostrou diferenças significativas no que se refere ao aumento do diâmetro dos feixes e das fibras musculares. Verificou-se aumento significativo no diâmetro das fibras $(\mathrm{F}=20.7716$ e $P<0,0001)$ e dos feixes musculares $(\mathrm{F}=8.8718$ e $P<0,0001)$ de todos os espécimes expostos (Figuras 5 e 6 ) a concentrações de sal marinho (AS), quando comparado com os espécimes de água doce $(\mathrm{AD})$.

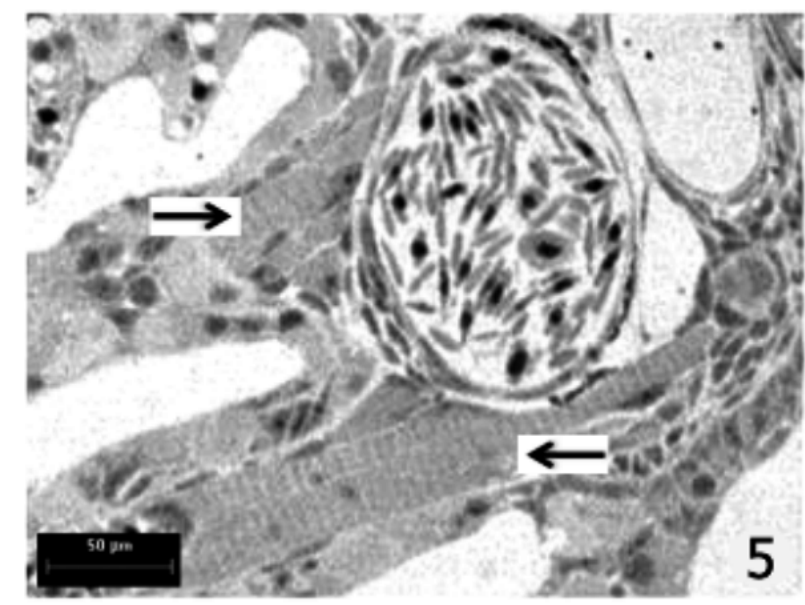

Ao comparar cada tratamento de AS com o grupo controle (AD), verificou-se que a maior diferença foi apresentada pelos grupos de 15\% e $20 \%$, ou seja, o maior aumento no diâmetro das fibras e feixes musculares durante a exposição à salinidade foi observada na exposição a 15 e 20 ppm. Os dados referentes à variação no diâmetro das fibras e feixes musculares são apresentados nas Figuras 7 e 8.

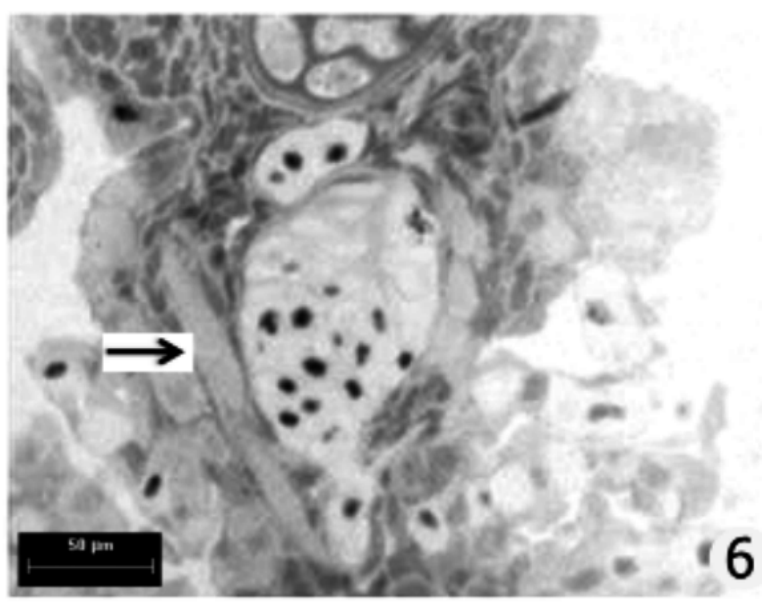

Figuras 5 e 6. Fotomicrografias evidenciando o aumento no diâmetro das fibras e feixes do músculo estriado esquelético branquial em presença de salinidade. 7. Músculo branquial de alevino exposto a $15 \mu 1 / \mathrm{L}$ de sal marinho (setas). Barra $=50 \mu \mathrm{m}$. 8. Músculo branquial de alevino exposto a $0 \mu \mathrm{l} / \mathrm{L}$ de salinidade (setas). Barra $=50 \mu \mathrm{m}$.

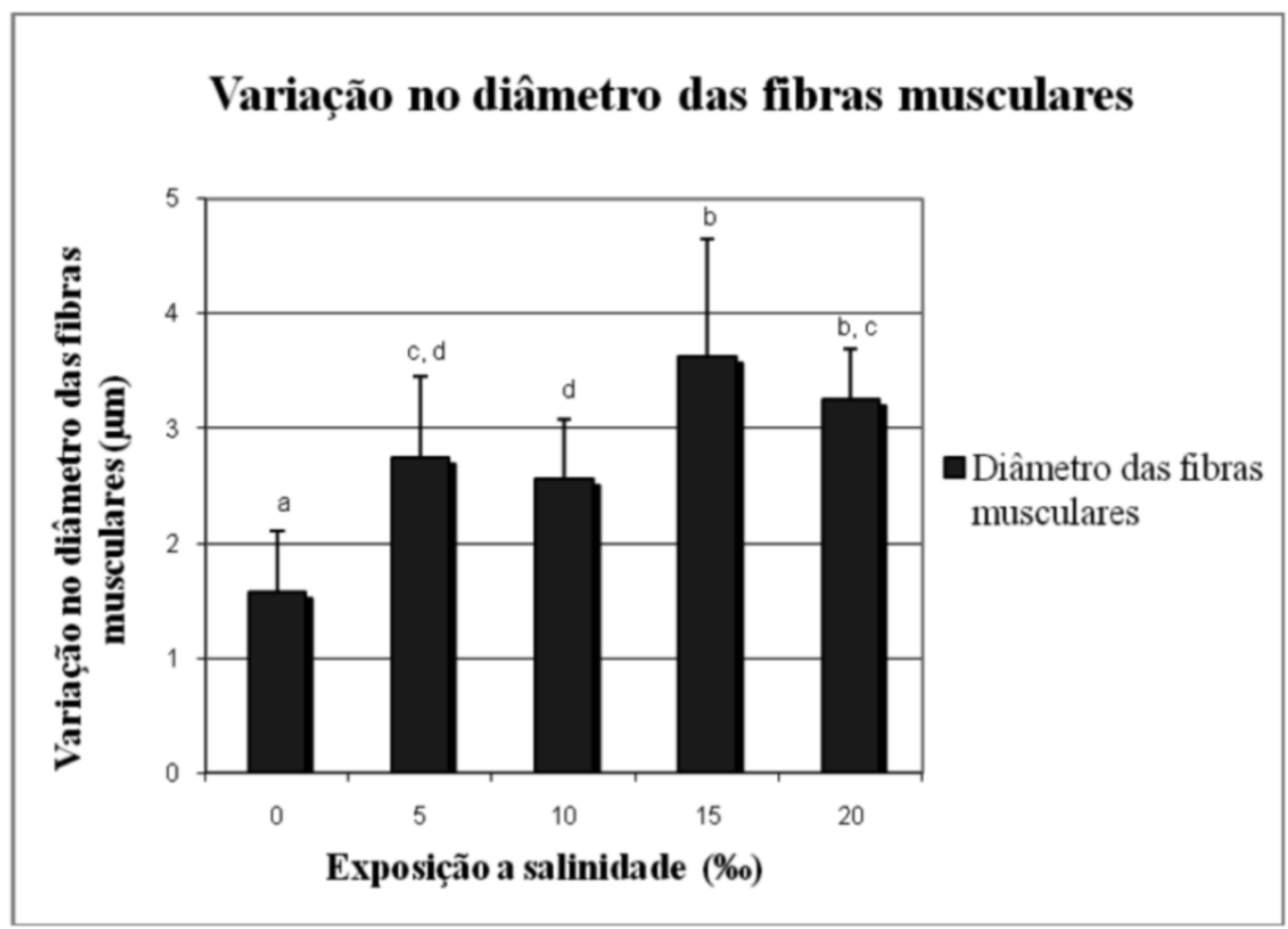

Figura 7 - Diâmetro das fibras musculares branquiais de alevino (P. vivipara). É possível observar a diferença entre o grupo controle em AD (a) e os tratamentos em AS (b, c, d). O grupo de 15 e 20\%o de salinidade apresentaram as fibras musculares branquiais com maior diâmetro quando comparadas com as fibras do grupo controle. 


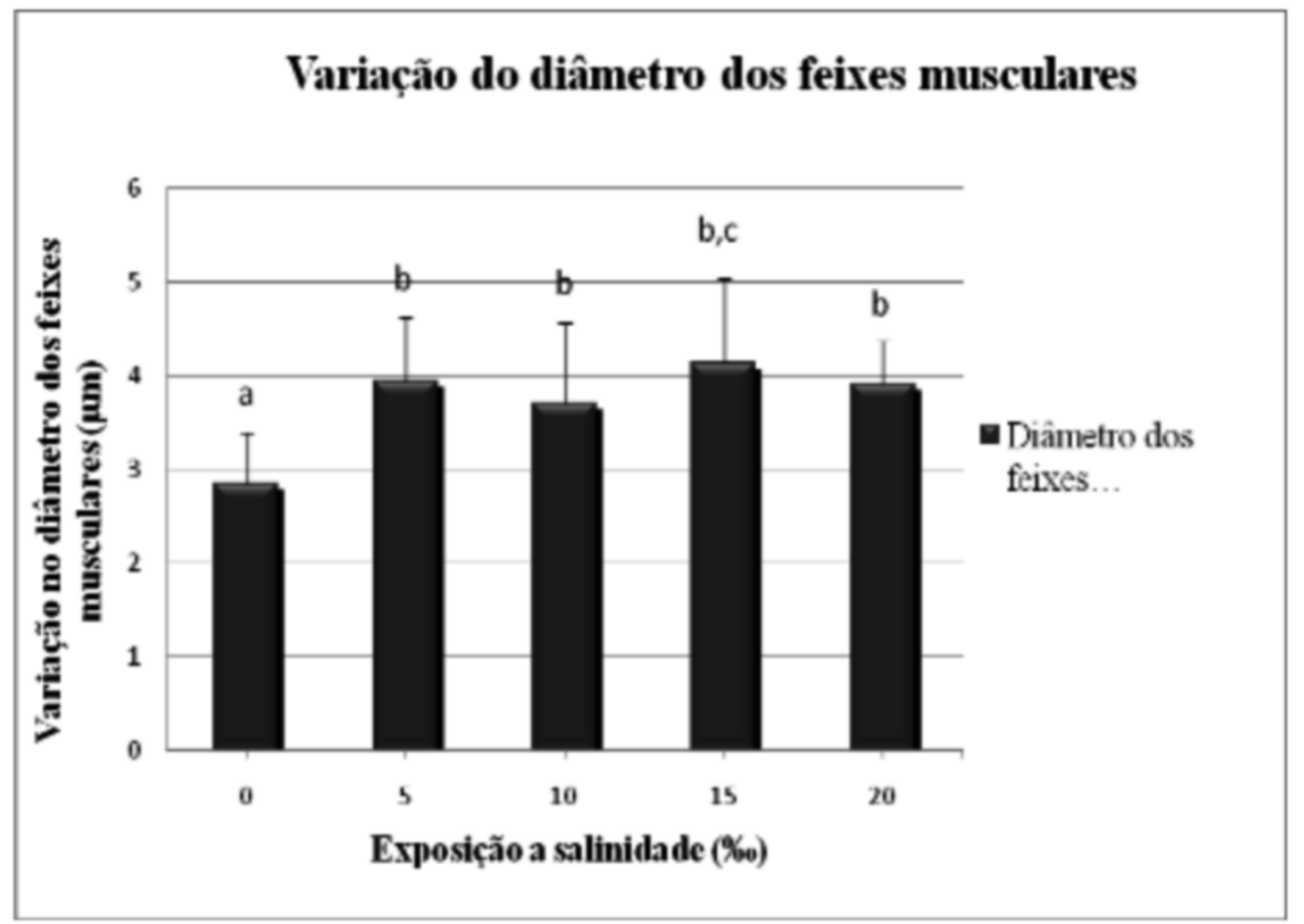

Figura 8 - Diâmetro dos feixes musculares branquiais de alevino (P. vivipara). É possível observar a diferença entre o grupo controle (a) e os tratamentos em AS (b). O grupo de 15\%o de salinidade apresentou os maiores feixes musculares branquiais, quando comparandos os feixes musculares de todos os tratamentos com os feixes musculares do grupo controle.

Tabela 1 - Média \pm Desvio padrão do diâmetro $(\mu \mathrm{m})$ das fibras e feixes musculares branquiais dos alevinos após a exposição por 2 horas a diferentes salinidades

\begin{tabular}{cccccc}
\hline Salinidade & $0 \%$ o & $5 \%$ o & $10 \%$ o & $15 \%$ o & $20 \%$ o \\
\hline Fibras musculares & $1,57 \pm 0,53$ & $2,74 \pm 0,70$ & $2,55 \pm 0,51$ & $3,62 \pm 1,02$ & $3,25 \pm 0,44$ \\
Feixes musculares & $2,85 \pm 0,54$ & $3,93 \pm 0,69$ & $3,71 \pm 0,84$ & $4,13 \pm 0,89$ & $3,91 \pm 0,46$ \\
\hline
\end{tabular}

Os dados obtidos acerca da caracterização morfológica do músculo estriado esquelético branquial estão de acordo com os descritos por BULERSON et al. (2001). Segundo esse autor, dois conjuntos de músculos estão ligados ao arco cartilaginoso que suporta as brânquias, os músculos abdutores que se localizam entre as bases do filamento do arco branquial e os músculos adutores que estão localizados entre as hemibrânquias. A atividade desse conjunto de músculos permite que a extração de oxigênio da água ocorra de forma eficiente.

No guaru, a partir da fase 3 de desenvolvimento já é possível observar esse conjunto de músculos branquiais, seguindo a mesma morfologia proposta por BULERSON et al. (2001). Essa organização morfológica do tecido muscular branquial é também observada em espécimes adultos de guaru.

Ao longo dos estágios de embrião, larva e alevino, foi possível observar o aumento gradual no diâmetro dos feixes musculares branquiais. Segundo WEATHERLEY et al. (1988), o desenvolvimento da musculatura depende dos processos de hipertrofia e de hiperplasia. A hiperplasia e a hipertrofia são mecanismos regulados por fatores moleculares (WATABE et al., 2001). Os genes reguladores têm uma taxa de expressão mais elevada durantes as etapas iniciais de desenvolvimento e controlam a proliferação das células miogênicas progenitoras, o que corresponde ao processo de hiperplasia. Já outras ações moleculares mediadas por proteína controlam a diferenciação e fusão dos mioblastos para formar as miofibras, processo de hipertrofia. De acordo com WEATHERLEY et al. (1988), em espécies de pequeno porte, o crescimento muscular envolve principalmente hipertrofia das fibras formadas no embrião durante o início da fase larval. Dessa forma, supõe-se que o aumento do diâmetro dos feixes musculares branquiais do $P$. vivipara ao longo das 
fases de desenvolvimento ocorre através do mecanismo de hipertrofia. No entanto, o processo de crescimento muscular do guaru precisa ser melhor estudado.

Quanto aos mecanismos de contração muscular, as fibras musculares branquiais são controladas pelo sistema nervoso central (MARK et al., 2001), modificando a posição do filamento branquial durante a ventilação. No entanto, o padrão de contração muscular não é bem definido durante o ciclo respiratório. PASZTOR \& KLEEREKOPER (1962) observaram, que os músculos abdutores e adutores contraem-se uma vez durante o ciclo ventilátorio. Já BALLINTIJN et al. (1983) afirmaram que esses músculos contraem-se duas vezes a cada ciclo. Em $P$. vivipara ainda não é determinado o número de contrações musculares durante o ciclo respiratório; entretanto, a contração do músculo branquial é de extrema importância para a respiração branquial.

Foi verificado também que ocorre um aumento no diâmetro das fibras e dos feixes musculares dos espécimes quando são expostos à salinidade. Esse resultado está de acordo com os dados descritos por BIZERRIL \& PRIMO (2001), que relacionaram o tamanho corporal dos guarus com o grau de salinidade do ambiente onde vivem, mostrando que espécimes de $P$. vivipara coletados em AS apresentaram maior tamanho e massa corporal do que aqueles coletados em AD.

$\mathrm{O}$ aumento do diâmetro das fibras e dos feixes musculares devido à salinidade pode ser explicado por mecanismos fisiológicos. BOEUF \& PAYAN (2001) sugerem que pode haver mais de um mecanismo envolvido nesse aumento, como redução na taxa metabólica basal, aumento da taxa de alimentação, aumento na conversão de alimentos e otimização da osmorregulação em salinidades ótimas. Como os alevinos de $P$. vivipara não possuem alimentação exógena nos períodos iniciais de livre natação, supõe-se que outros mecanismos não alimentares devem ser responsáveis pelo aumento no diâmetro das fibras e feixes musculares.

A diferença nos gradientes de salinidade modifica os mecanismos de osmorregulação. Os peixes em $A D$ ou com salinidade reduzida perdem de forma passiva íons para o meio, e essa perda deve ser compensada pela entrada de íons oriundos do ambiente onde estão e a dieta passa a ser a principal fonte de sais (SMITH et al., 1989). Em concentrações de salinidade ótimas, próximos ao ponto isosmótico, os peixes apresentam uma demanda energética menor para a osmorregulação, uma vez que há também a minimização do consumo de oxigênio, e essa energia poupada pode ser canalizada para outros processos do desenvolvimento somático e então acelerar o crescimento (BOEUF \& PAYAN, 2001). Dessa forma, supõe-se que os alevinos de Poecilia vivipara expostos à salinidade aumentaram o diâmetro das fibras e feixes musculares devido a mecanismos de osmorregulação.

Sugere-se que os alevinos expostos a concentrações de salinidade próximas a 15 e $20 \%$ pode ter reduzido o gasto energético no processo de osmorregulação, devido a esse gradiente representar um ponto isosmótico em relação aos fluídos corporais, disponibilizando, dessa forma, mais energia para o desenvolvimento muscular branquial. Esses dados estão de acordo com AMARAL et al. (2001), que afirmaram que a maior atividade da bomba de sódio e potássio ocorre em $20 \%$ de salinidade, e que esta é a melhor salinidade para o cultivo de $P$. vivipara.

No entanto, a diferença no diâmetro das fibras e feixes musculares desse tratamento comparado com os demais grupos expostos à salinidade não foi estatisticamente significativa, provavelmente porque o tempo de exposição foi de apenas 2 horas.

O conhecimento dos efeitos da salinidade nas características musculares é importante porque os guarus são espécimes que habitam águas continentais, como lagoas, e estas podem esporadicamente se comunicar com os oceanos através das aberturas de barras, formando gradientes de salinidade (BIZERRIL \& PRIMO, 2001). Segundo SUZUKI et al. (2002), uma mesma lagoa pode apresentar diferentes gradientes de salinidade ao longo da sua extensão, o que expõem essa espécie constantemente a variações de salinidade. Dessa maneira, os alevinos, mesmos nos momentos iniciais de livre natação, necessitam que as estruturas branquiais, com seus respectivos tipos celulares, estejam formadas e aptas a exercerem suas funções vitais.

A compreensão da influência da salinidade no tecido muscular possui relevância também na área da aquicultura, uma vez que o estabelecimento do gradiente de salinidade isosmótico pode maximizar o crescimento de espécies com valor comercial. Assim, conhecimentos adquiridos nessa área por meio de estudos com espécies modelos como o guaru podem também ser utilizados para melhorar a criação de peixes para consumo na alimentação.

\section{CONCLUSÃO}

Neste trabalho foi possível caracterizar que a ontogênese do músculo estriado esquelético branquial do $P$. vivípara ocorre nos embriões, período entre as fases 2 e 3 do desenvolvimento. Os músculos branquiais correspondem a um conjunto de 
músculos inseridos no arco cartilaginoso que suporta as brânquias, sendo eles os músculos adutores que se localizam entre as bases dos filamentos branquiais e os músculos abdutores que se prolongam ao longo dos filamentos branquiais. Esse conjunto muscular sofre modificações quando os espécimes são expostos a diferentes salinidades. Em salinidades ótimas, próximas a $15 \mu \mathrm{1} / \mathrm{L}$, ocorre o aumento do diâmetro das fibras e feixes musculares.

\section{REFERÊNCIAS}

AMARAL, M.C; BONECKER, A.C.T. ORTIZ, C.H.D. Activity Determination of $\mathrm{Na}+\mathrm{K}+$ - ATPase and $\mathrm{Mg}++$ ATPase Enzymes in the Gill of Poecilia vivipara (Osteichthyes, Cyprinodontiformes) in Different Salinities Brazilian Archives of Biology and Technology, v.44, n.1, p.1 - 6, 2001.

BALLINTIJN, C.M. The respiratory function of gill filament muscles in the carp. Respiration Physiology, v.60, n.1, p.59-74, 1985.

BALLINTIJN, C.M., ROBERTS, B.L., LUITEN, P.G.M., Respiratory responses to stimulation of branchial vagus nerve ganglia of a teleost fish. Respiration Physiology, v.51, p.241-257, 1983.

BEASTER-JONES, L.; HORTON, A.C; GIBSONBROWN, J.J; HOLLAND, N,D; HOLLAND, L. Z. The amphioxus T-box gene, AmphiTbx15/18/22, illuminates the origins of chordate segmentation Evolution \& Development, v.8, n.2, p.119-129, 2006.

BIZERRIL, C. R. S. F. PRIMO, P. B. S. Peixes de águas interiores do Estado do Rio de Janeiro. FEMARSEMADS, Rio de Janeiro, 2001. 417p.

BOUEF, G. PAYAN, P. How should salinity influence fish growth? Comparative Biochemistry and Physiology Part C, v.130, p 411-423, 2001.

BURLESON, M. L.; SMITH, R. L. Central nervous control of gill filament muscles in channel catfish. Respiration Physiology, v.126, p.103-112, 2001.

CARVALHO NETO, M.B.; TOURINHO, E.Z. Notas sobre a dicotomia "inato" versus "aprendido". InterAção, v.5, p.123-132, 2001.

DÍAZ, A.O.; GARCÍA, A.M.; DEVINCENTI, C.V.; GOLDENBERG, A.L. Ultrastructure and histochemical study of glycoconjugates in the gills of the White Croaker (Micropogonias funieri). Anatomia Histologia Embriologia, v.34, p.117-122, 2005.

DRIEDZIC, W.R., HOCHACHKA, P.W., Control of energy metabolism in fish white muscle. American Journal of Physiology, v.230, p.579-582, 1976.

HAWKE TJ, GARRY DJ. Myogenic satellite cells: physiology to molecular biology. Journal Applied Physiology, v.9, n.2, p.534-51, 2001.

JOBLING M. Osmotic and ionic regulation-water and salt balance. Environmental biology of fishes. Chapman \& Hall Press, 1995. p.211-249.

JOHNSTON, I.A., Muscle development and growth: potential implication for flesh quality in fish. Aquaculture, v.177, p.99-115, 1999.

JONHSTON, I.A., DAVISON, W., GOLDSPINK, G. Energy metabolism of carp swimming muscles. Journal of Comparative Physiology, v.114, p.203-216, 1977.

LAURENT, P.; H. HOBE; S. DUNEL. The role of environmental sodium chloride relative to calcium in gill morphology of freshwater salmonid fish. Cell and Tissue Research, v.240, p.675-692, 1985.

LUTHER, P.K., MUNRO, P.M.G., SQUIRE, J.M. Muscle ultrastructure in the teleost fish. Micron, v.26, p.431-459, 1985.

BURLESON, M.L., SMITH, R.L. Central nervous control of gill filament muscles in channel catfish. Respiration Physiology, v.126, p.103-112, 2001.

MOLYLE P.B. \& J.C. CECH JR. Fishes: An Introduction to Ichthyology. New Jersey: Chapman \& Hall, 1996. 579p.

PASZTOR, V.M., KLEEREKOPER, H., The role of the gill filament musculature in teleosts. Canadian Journal of Zoology, v.40, p.785- 802, 1962.

PETER, J.B.; BARNARD, R.J.; EDGERTON, V.R.; GILLESPIE, C.A.; STEMPEL, K.E. Metabolic profiles of three fiber types of skeletal muscle in guinea pigs and rabbits. Biochemistry v.11, p.2627-37, 1972.

RANTANEN J, HURME T, LUKKA R, HEINO J, KALIMO H. Satellite cell proliferation and the expression of myogenin and desmin in regenerating skeletalmuscle: evidence for two different populations of satellite cells. Laboratory Investigation, v.72, n.3, p.341-7, 1995.

SABÓIA-MORAES, S.M.T.; HERNANDEZBLAZQUEZ, F.J; MOTA, D.L.; BITTENCOURT, A.M. Mucous cell types in the branchial epithelium of the euryhaline fish Poecilia vivipara. Journal of Fish Biology, v.49, p.545-548, 1996.

SALES, R. O.; SALES, A. M. Estudo da composição química e rendimento de dez espécies de pescado de água doce de interesse comercial nos açudes do Nordeste Brasileiro. Ciência Agronômica, v. 21, n. 1/2, p. 27-30, 1990.

SANTOS, V.B. Aspectos morfológicos da musculatura lateral dos peixes. Boletim do Instituto de Pesca, v.33, n.1, p.127 - 135, 2007.

SARTORI, J.R.; GONZALES, E.; DAL PAI, V. OLIVEIRA, H.N.; MACARI, M. Efeito da temperatura ambiente e da restrição alimentar sobre o desempenho e composição de fibras musculares esqueléticas de frangos de corte. Revista Brasileira de Zootecnia, v. 30, n. 6, p. 1779-1790, 2001.

SCHULTZ, E.; McCORMICK, K. M.. Skeletal Muscle Satellite Cells. Reviews of Physiology, Biochemistry \& 
Pharmacologyv.123, 1994.

SMITH, N.F.; TALBOT, C.; EDDY, F.B. Dietary salt intake and its relevance to ionic regulation in freshwater salmonids Journal of Fish Biology, v.35, p.749-753, 1989.

SUZUKI, M. S.; OVALlE, A. R. C.; PEREIRA, E. A. Effects of sand bar openings on some limnological variables in a hypertrophic tropical coastal lagoon of Brazil. Hydrobiologia, v.368, p.111-122, 1998.

VARSHNEY, C.K. (Ed.) Water pollution and managements. New Delhi, Wiley Eastern. 1991. p. 88-9.

VIGLIANO, F.A.; ALEMAN, N.; QUIROGA, M.I.; NIETO, J.M. Ultrastructural Characterization of Gills in Juveniles of the Argentinian Silverside, Odontesthes bonariensis (Valenciennes, 1835) (Teleostei: Atheriniformes). Anatomia Histologia Embriologia, v.35, p.76-83, 2006.

WATABE S. Myogenic regulatory factors and muscle differentiation during ontogeny in fish. Journal of Fish Biology, v.55, p.1-18, 1999.

WEATHERLEY, A. H.; GILL, H.S. and LOBO, A.F. Recruitment and maximal diameter of axial muscle fibers in the teleosts and their relationship to somatic growth and ultimate size. Journal of Fish Biology, London, v. 33, p.851-859, 1988.

ZHANG, G., SWANK, D.M., ROME, L.C.Quantitative distribution of muscle fiber types in the scup Stenoteomus chrysops. Journal of Morphology, v.229, p.71-81, 1996. 